\title{
Circunstancias externas
}

\section{y reequilibrio económico del contrato público. ¿Nuevas perspectivas?}

\author{
ISABEL GALLEGO ${ }^{1}$
}

\section{RESUMEN}

La legislación española ha reconocido tradicionalmente el derecho del concesionario a mantener el equilibrio económico del contrato, derecho que se ha extendido jurisprudencialmente a todo tipo de contrato público. No obstante, el nuevo derecho de la contratación pública de la Unión Europea impone severos límites a la modificación tanto de contratos como de concesiones. El objetivo principal de este trabajo es analizar si como consecuencia de este derecho global se han introducido matices a la doctrina del riesgo imprevisible, tal y como ha sido entendida en el derecho nacional español.

1 Doctora en Derecho y profesora titular de Derecho Administrativo, Universidad de CastillaLa Mancha, Ciudad Real, España. Correo-e: isabel.gallego@uclm.es. Fecha de recepción: 2 de febrero de 2016. Fecha de modificación: 15 de abril de 2016. Fecha de aceptación: 16 de mayo de 2016. Para citar el artículo: Gallego, I. (2016). Circunstancias externas y reequilibrio económico del contrato público. ¿Nuevas perspectivas? Revista digital de Derecho Administrativo n. ${ }^{\circ}$ 15, primer semestre, Universidad Externado de Colombia, pp. 115-142. DOI: http://dx.doi.org/10.18601/21452946.n15.07

Siglas utilizadas: ACP (Acuerdo sobre Contratación Pública, Organización Mundial del Comercio, 1994); IJCCA (Informe Junta Consultiva de Contratación Administrativa); RSCL (Reglamento de Servicios de las Corporaciones Locales de 17 de junio de 1955); STGUE (Sentencia del Tribunal General de la Unión Europea); STJUE (Sentencia del Tribunal de Justicia de la Unión Europea); STS (Sentencia del Tribunal Supremo); STSJ (Sentencia del Tribunal Superior de Justicia); TJUE (Tribunal de Justicia de la Unión Europea); TRLCAP (Real Decreto Legislativo 2/2000, de 16 de junio, por el que se aprueba el Texto refundido de la Ley de Contratos de las Administraciones Públicas); TRLCSP (Real Decreto Legislativo 3/2011, de 14 de noviembre, por el que se aprueba el Texto refundido de la Ley de Contratos del Sector Público); TS (Tribunal Supremo); TSJ (Tribunal Superior de Justicia). 
Palabras clave: derecho de la Unión Europea, derecho administrativo, contrato administrativo, doctrina jurídica, interpretación del derecho, equilibrio económico del contrato, concesiones.

\title{
External Facts and Economic Balance of the Public Contract. In Need of a New Approach?
}

\begin{abstract}
Spanish Law has traditionally recognized the right of the concessionaire to maintain the economic balance of a contract. Case law has extended this right to all types of public contracts. However, the new the European Union Directives on public procurement impose severe limits on the modification of both contracts and concessions. The main objective of this paper is to analyze whether as a result of this global law the doctrine of unpredictable risk, as it has been understood in our national law, needs to be revised.

Keywords: Application of Eu Law, Public Procurement, Legal Doctrine, Economic Balance of the Contract, Concessions.

\section{INTRODUCCIÓN. EL RECONOCIMIENTO DE LAS TÉCNICAS DE GARANTÍA DEL EQUILIBRIO FINANCIERO DEL CONTRATO EN EL DERECHO ESPAÑOL}

Los contratos públicos se celebran a riesgo y ventura del contratista. Sin embargo, ello no ha impedido que se hayan gestado técnicas de garantía del equilibrio económico-financiero del contrato cuya virtualidad ha sido el mantenimiento del contrato mismo ante determinadas circunstancias que, en el caso de la teoría de la imprevisión o del riesgo imprevible y del factum principis, tienen carácter externo al contrato².

2 GarCía de ENTERRÍA y FeRnáNDEZ (2000, p. 731). La doctrina de la teoría de la imprevisión se formuló por ARIÑO (1968, p. 291) en los siguientes términos: "cuando circunstancias imprevistas en el momento de la conclusión del contrato vienen a trastornar la economía del mismo con la gravedad, que lo hace, si no imposible, mucho más difícil y oneroso, por encima de lo que las partes han podido razonablemente prever; cuando el déficit, sobrepasando los límites el riesgo normal, toma un carácter anormal y excepcional, entonces el contratante de la Administración tiene el derecho de pedirle que venga en su ayuda para repartir con él el riesgo extraordinario mediante una indemnización calculada en función del déficit, que el compense en parte de él. La teoría de la imprevisión no se refiere, por 
En efecto, la doctrina del equilibrio económico del contrato se ha aplicado tradicionalmente en derecho español al margen de su reconocimiento legal, como uno de los principios generales de nuestra contratación. De hecho, el desarrollo pleno de esta doctrina se encuentra en el artículo 127.2. 2. ${ }^{\circ}$ Reglamento de Servicios de las Corporaciones Locales de 17 de junio de 1955, artículo que, todavía en vigor, establece que la corporación deberá mantener el equilibrio financiero de la concesión, para lo cual "revisará las tarifas y subvención cuando, aun sin mediar modificaciones en el servicio, circunstancias sobrevenidas e imprevisibles determinaren, en cualquier sentido, la ruptura de la economía de la concesión".

De forma consecuente, la jurisprudencia del Tribunal Supremo ha reconocido (ver, p. ej., STS de 19 de septiembre de 2000 y jurisprudencia allí citada) el mantenimiento del equilibrio económico de las concesiones administrativas como un principio básico de toda figura concesional -y no sólo propia de los contratos de servicios-, amparado en las previsiones contenidas en los artículos $116.3,127.2 .2$ a) y b), 129.3 y 5 y 152 RCSL.

Más aún, el reconocimiento del principio del mantenimiento del equilibrio económico del contrato no se ha limitado al ámbito concesional, estando ínsito en todo tipo de contratos administrativos. Basta comprobar así cómo la jurisprudencia española lo ha reconocido en el ámbito del contrato de obras, y ello aunque, en este caso, no encuentre sustento normativo. De este modo, el equilibrio económico del contratista se ha caracterizado como fondo institucional del contrato administrativo ${ }^{3}$. Dicho en otros términos, por razones de equidad, el Tribunal Supremo ha admitido con normalidad la necesidad de compensar al contratista en los supuestos en los que un acontecimiento anormal e imprevisible provoca un incremento de la onerosidad del contrato. Aunque en determinados supuestos - como es el caso del contrato de obrasesta posibilidad no se admita expresamente por la legislación aplicable ${ }^{4}$.

supuesto, a las dificultades ordinarias en el cumplimiento del contrato, por recargo de abastecimientos de materias primas, desperfectos de las máquinas, variaciones ordinarias de preciso, etc.; son todos ellos riesgos normales de toda empresa, cuyas consecuencias se hallan a cargo de los empresarios, que no puedan hacerlas recaer sobre la Administración".

Aunque el derecho de la Unión Europea distingue entre contratos y concesiones como conceptos diferentes, en este trabajo seguimos la orientación clásica de la doctrina y la jurisprudencia españolas considerando la concesión como una especie del género contrato público

4 Ver SSTS de 16 de septiembre de 1988 y de 17 de diciembre de 1997. A mayor abundamiento el IJCCA 61/08, de 31 de marzo de 2009, considera que se ha producido un supuesto de reequilibrio económico del contrato en virtud de la doctrina del factum principis, pese a que el artículo 163 TRLCAP (aplicable ratione temporis) no contemplaba expresamente esta figura, a diferencia del vigente artículo 258 TRLCSP. Igualmente, la STSJ de Madrid de 28 de febrero de 2013 (rec. 1360/2010) tiene ocasión de afirmar que el restablecimiento económico del contrato se viene a configurar como un principio general aplicable en materia de contratación administrativa. 
En definitiva, como afirma el IJCCA Aragón de 24/2013, de 25 de noviembre, "en todo contrato, con independencia de su naturaleza jurídica, se ha de procurar que las prestaciones que las partes se obligan a dar, entregar o recibir resulten equivalentes desde el punto de vista económico" ${ }^{\prime \prime}$.

Los principales requisitos para la aplicación de la doctrina del riesgo imprevisible como técnica del equilibrio del contrato fueron ya enunciados en la STS de 26 de diciembre de 1990. De esta forma, cuando la revisión de precios devine ineficaz,

... por concurrir otros hechos que escapan a las previsiones normativas establecidas al efecto, produciendo con ello en la relación jurídico-contractual que vincula a las partes, un desequilibrio económico de tal entidad y naturaleza que, el cumplimiento por el contratista de sus obligaciones derivadas de ella, sea excesivamente oneroso para el mismo, el cual razonablemente no pudo precaver, incluso empleando una diligencia fuera de lo normal en este tipo de contrataciones, entonces y en este último supuesto ha de acudirse a la aplicación de la doctrina de "riesgo razonablemente imprevisible", como medio extraordinario, como extraordinarias son sus causas, para restablecer el equilibrio económico del contrato ${ }^{6}$.

Mucho más recientemente, la STS de 18 de abril de 2008 explica que la doctrina del riego imprevisible, enlazada a la de la cláusula rebus sic stantibus, exige que, como consecuencia de la aparición de un riesgo que no pudo ser previsto al tiempo de celebrarse el contrato, se alteren sustancialmente las condiciones de ejecución del mismo, de modo que la prestación pactada resulte mucho más onerosa para una de las partes de lo que inicialmente podía preverse.

En definitiva, aunque la determinación de cuándo procede el reequilibrio económico del contrato es sumamente casuística, una lectura detenida de la jurisprudencia recaída hasta la fecha permite concluir que son tres los requisitos que han de concurrir para que una circunstancia determinada constituya

5 Y es que, como señala el citado informe, "el equilibrio económico financiero del contrato es un criterio rector en un contrato de gestión indirecta de servicio público, o de concesión de obra pública, de forma que los costos de inversión y gestión del servicio o de la obra puedan ser resarcidos con el margen de beneficio pactado mediante el cobro, entre otras posibles fuentes de ingresos, de las tarifas que abonarán los usuarios del servicio. Cuando el desequilibrio en la explotación de una concesión no es imputable al concesionario, y éste ha desarrollado una buena y ordenada administración, para amortizar el costo de establecimiento del servicio, cubrir los gastos de explotación y un margen normal de beneficio industrial, se debe reequilibrar el contrato con el fin de mantener, en estas nuevas condiciones imprevisibles, la TIR incorporada al contrato".

6 En el mismo sentido, la STS de 9 de marzo de 1999 añade que "la indicada doctrina del 'riesgo imprevisible razonable', se construye sobre un elemento importante que no puede ser matemáticamente determinado para todos los supuestos, ya que se encuentra en función de su acusada 'relevancia y significación' en el contexto total de la contratación de que se trate y a cada caso en que aquélla se aplique; y en el caso de autos se halla acreditado". 
un hecho imprevisible que obligue a la Administración a reequilibrar económicamente el contrato:

a) Que se produzca un acontecimiento que desborde las previsiones razonables;

b) Que dicho acontecimiento sea independiente de la gestión empresarial realizada por el contratista, $\mathrm{y}$

c) Que, como consecuencia del acontecimiento imprevisible, se alteren sustancialmente las condiciones de ejecución del contrato, de modo que la prestación pactada resulte mucho más onerosa para una de las partes de lo que inicialmente podía preverse. De esta forma, se exige que la circunstancia imprevisible tenga un impacto relevante y significativo en la economía del contrato.

Por su parte, el estudio atento de la jurisprudencia y de la doctrina administrativa pone de manifiesto que, al margen del distinto origen del evento que produce el desequilibrio económico del contrato, los requisitos para la aplicación de la doctrina del factum principis no son muy diferentes a los que son exigidos en relación con la aplicación doctrina del riesgo imprevisible.

En efecto, el factum principis alude a medidas administrativas generales que, aunque no modifiquen directamente el objeto del contrato, ni lo pretendan tampoco, inciden o repercuten sobre él haciéndolo más oneroso para el contratista sin culpa de este. Como es definido por la sentencia de 2 de diciembre de 1985, el factum principis "contempla el supuesto de que la adopción de medidas administrativas al margen del mismo contrato suponga una repercusión indirecta en el ámbito de sus relaciones contractuales que haga en exceso oneroso la prestación del contratista".

En suma, para que proceda el restablecimiento del equilibrio económico del contrato en virtud de la aplicación de la doctrina del factum principis es preciso:

a) Que la causa del desequilibrio proceda de la voluntad de los entes públicos, sin que pueda ser imputada a una mala gestión por parte del contratista;

b) Que dicha causa sea imprevisible, requisito que ha de valorarse caso a caso, teniendo siempre presentes las exigencias de la buena fe contractual, y

c) Que, como consecuencia de las medidas adoptadas, se haya incrementado la onerosidad del contrato. A diferencia de la teoría del riesgo imprevisible, la jurisprudencia no exige de forma contundente que el desequilibrio haya sido relevante y significativo, sino simplemente que 
exista la correspondiente relación de causalidad entre la decisión administrativa general y el perjuicio irrogado al concesionario ${ }^{7}$.

En los últimos años, la situación económica atravesada por España ha propiciado la gestación de un relevante cuerpo jurisprudencial sobre la doctrina del riesgo imprevisible y, ligado al anterior, al factum principis. Un primer grupo de supuestos han sido aquellos en los que la solicitud se ha basado en la situación de grave crisis económica atravesada por la economía española. En este caso, la STS de 30 de junio de 2014 (Sala de lo Civil, rec. 2250/2012) ha estimado, como hecho notorio, que la crisis económica, de efectos profundos y prolongados de recesión económica, puede ser considerada abiertamente como un fenómeno de la economía capaz de generar un grave trastorno o mutación de las circunstancias y, por tanto, alterar las bases sobre las cuales la iniciación y el desarrollo de las relaciones contractuales se habían establecido. De esta forma, reconoció el derecho al reequilibrio solicitado por el contratista ${ }^{8}$. Sin

7 En nuestra jurisprudencia se han considerado como causa de restablecimiento del equilibrio económico del contrato: la inaplicación de la Ordenanza municipal reguladora del tráfico [STS de 6 de abril de 2005 (rec. 7428/2001)]; la habilitación de nuevos aparcamientos en superficie constituye un elemento externo en relación con una concesión de aparcamiento subterráneo [STSJ de Justicia de Cataluña 14 de diciembre de 2006 (rec. 956/2006)]; el cambio en la política deportiva de un Ayuntamiento [STSJ de la Región de Murcia de 10 de junio de 2013 (rec. 55/2013)]; la ausencia de realización de una obra prevista en el Plan de Infraestructuras y Transportes [STS de 16 de mayo de 2011 (rec. 566/2008)].

En la doctrina de los órganos consultivos, el IJCCA Estado 61/2008, de 31 de marzo de 2009, considera que la realización de unas obras derivadas de nuevas exigencia impuestas por la nueva normativa medioambiental configura un supuesto de factum principis. Por su parte, el IJCCA Aragón 24/2013, de 25 de noviembre, reconduce al factum principis la apertura de nuevas infraestructuras no previstas en la memoria económica.

8 Describimos este supuesto de hecho en la nota 53. En el mismo sentido, el IJCCA Aragón 8/2013, de 10 de abril, y el IJCCA Aragón 18/2012, de 19 de septiembre, consideran que la crisis económica, que ha afectado de manera muy relevante el equilibrio económico de los contratos de gestión de servicios públicos, puede ser considerada causa o riesgo imprevisible susceptible de generar el correspondiente derecho del concesionario al reequilibrio económico del mismo. En concreto, el IJCCA Aragón 15/2013, de 26 de junio, concluye que la incidencia de la crisis económica permite la modificación del contrato ahí analizado (en el supuesto, un negocio jurídico patrimonial por el que se posibilita al contratista la explotación de la actividad minera de extracción de áridos). En especial, es elocuente en este sentido el IJCCA Aragón 24/2013, de 25 de noviembre, según el cual: "El principio de mantenimiento del equilibrio económico financiero debe aplicarse de forma prudente. Ahora bien, aplicación prudente no significa aplicación en forma restrictiva, como si este último principio viniera recogido en normas de carácter excepcional: existe un verdadero derecho del concesionario al mantenimiento del equilibrio económico financiero de su concesión, como derecho a atenuar los rigores del riesgo concesional ante determinadas circunstancias y mediante determinadas técnicas que deben, eso sí, ser aplicadas con prudencia. Así, en la medida en que la actual situación de crisis económica impacte de forma desproporcionada - por alterarse la realidad en que se fundamentaron las previsiones del objeto del contrato y sobre las que responsablemente formuló la proposición el licitador-, 
embargo, frente a ello, distintas SSTS de la Sala de lo Contencioso-Administrativo relativas al grave descenso en el tráfico de determinadas infraestructuras viarias han desestimado las solicitudes de compensación reclamadas por los concesionarios ${ }^{9}$, considerándose que si ambas partes contratantes erraron de forma amplia en sus cálculos por no prever factores que podían afectar a los mismos (la paralización/disminución del desarrollo urbanístico en el entorno atendido, la crisis económica que reduce la movilidad, las actuaciones de infraestructura puestas de relieve por el perito) no puede ahora la concesionaria imputar tal error a la administración.

Por su parte, la STS de 16 de mayo de 2011 (rec. 566/2008) ha entendido procedente el reequilibrio económico de un contrato de concesión de obras públicas por la falta de realización de una obra prevista en el Plan de Infraestructuras y Transporte, finalmente paralizada. Sin embargo, según esa misma sentencia, no constituye causa de reequilibrio el desdoblamiento de una carretera que discurre paralela a la autopista objeto de concesión ${ }^{10}$. Finalmente, la STS de 8 julio de 2015 (rec. 1534/2014) declara que la no realización de determinadas obras no hace surgir el derecho al restablecimiento económico del contrato en cuanto no se acredita que el pliego estableciese la obligación de la administración de su realización, sino que se limitó a considerar que pudiera darse cualquiera de las tres hipótesis incorporadas al estudio de viabilidad económico-financiera.

Finalmente, el mecanismo de reequilibrio, como se ha caracterizado tradicionalmente, puede jugar tanto a favor como en contra del contratista. Pues bien, de la STS de 16 de diciembre de 2013 (rec. 2882/2012) se desprende que la Administración no tiene derecho a reequilibrar el contrato a su favor si el tipo impositivo aplicable al contrato es inferior al previsto en la oferta.

Como puede advertirse, en los últimos pronunciamientos de la jurisprudencia española es reseñable una aproximación restrictiva al principio del equilibrio económico del contrato, habiéndose planteado en algunos casos expresamente si este es compatible con el derecho de la Unión Europea que el Reino de España debería transponer antes del 18 de abril de 2016. Y es que, por primera vez, el derecho europeo regula la modificación de los contratos públicos. Así, la Directiva 2014/24/UE del Parlamento Europeo y del Consejo de 26 de abril de 2014, sobre contratación pública ${ }^{11}$, y la Directiva 2014/23/ UE Parlamento Europeo y del Consejo de 26 de abril de 2014, sobre concesio-

sí resultaría posible un reajuste de las condiciones financieras de la concesión, si el sistema de retribución que se diseñó ha variado más allá de lo previsible, lo que influye directamente e indebidamente en las tasas de retorno de la inversión (TIR) previstas y pactadas en los contratos, y sobre las que se hace descansar el principio de riesgo de explotación".

9 Entre otras, SSTS de 20 abril de 2015 (rec. 54/2013) y 4 de febrero de 2014 (rec. 86/2011).

10 STS 4 de febrero de 2014 (rec. 86/2011).

11 Esta directiva se aplica a los contratos de obra cuyo valor estimado sea igual o superior 
nes ${ }^{12}$, contienen sendas disposiciones al efecto. Sin embargo, como se pretende argumentar en este trabajo, dicha normativa no desdibuja la posibilidad de reconocer el derecho del contratista a restablecer el equilibrio económico del contrato ante el acaecimiento de un hecho externo, sino que permite situarlo dentro de unos límites razonables.

\section{REEQUILIBRIO ECONÓMICO Y MODIFICACIÓN DEL CONTRATO EN EL DERECHO DE LA UNIÓN EUROPEA}

\section{LA DiRECTIVA 2004/18/UE Y LA IMPOSIBILIDAD DE ALTERAR EL CONTENIDO DEL CONTRATO ANTE EL ACAECIMIENTO DE UN RIESGO IMPREVISIBLE}

Las normas sobre contratación pública europeas tradicionalmente se han limitado a la fase de formación del contrato, así como a asegurar los recursos en caso de incumplimiento de las reglas relativas a esta etapa, porque se entendía que solamente esta fase podía tener incidencia en el establecimiento y funcionamiento del mercado interior. De esta forma, la Directiva 2004/18/UE -al igual que sus precedentes- no dedicaba precepto alguno a la modificación del contrato público.

Sin embargo, el desarrollo de la jurisprudencia comunitaria sobre las reglas de la contratación pública ha tenido ocasión de demostrar que la fase de ejecución del contrato también puede producir distorsiones en el funcionamiento del mercado interior, en la medida en que puede resultar idónea para favorecer a un competidor frente al resto, contraviniendo así los principios de igualdad de trato y transparencia en los que descansa el sistema de contratación público europeo. De nada sirve el respeto escrupuloso de estos principios en la fase de selección del adjudicatario si, una vez elegido este, puede alterarse el contenido de lo licitado en su beneficio ${ }^{13}$. Por ello, los límites a la modificación de los contratos se introdujeron por primera vez en el derecho de la Unión de forma pretoriana.

En este sentido, es ya célebre la STJUE de 29 de abril de 2004, Succbi di Frutta, asunto C-496/99, que tuvo su origen en un contrato licitado por la Comisión Europea para el suministro de zumos de frutas y confituras destinados a las poblaciones de terceros Estados. Según las condiciones iniciales de la contra-

a 5.225.000 euros y a los contratos de suministro y servicio cuyo estimado sea igual o superior a 209.000 euros (en estos casos rigen excepciones).

12 Esta directiva se aplica a las concesiones de obra y servicios cuyo valor estimado sea igual o superior a 5.225 .000 euros.

13 Como subrayan RACCA y CAVAllo Perin (2013, p. 280), para que la eficiencia en la contratación deje de ser un concepto abstracto, la ejecución del contrato por parte del adjudicatario debe coincidir con lo que prometió en la fase competitiva. 
tación, el pago se haría en manzanas o naranjas según el lote del que se tratase. No obstante, una vez adjudicados los contratos, la Comisión permitió a las empresas adjudicatarias que lo desearan aceptar en pago, en sustitución de las manzanas y las naranjas, otros productos retirados del mercado.

Para concluir que esta decisión era contraria a derecho el Tribunal de Justicia sólo tuvo que extender al momento de la ejecución contractual su doctrina sobre la igualdad de trato ${ }^{14}$. Y es que si se permite que la modificación del contrato afecte a las condiciones esenciales de la licitación se produciría "la vulneración de los principios de transparencia y de igualdad de trato entre los licitadores, puesto que la aplicación uniforme de las condiciones de licitación y la objetividad del procedimiento dejarían de estar garantizadas".

Para llegar a tal conclusión se parte de que si la entidad adjudicadora estuviera autorizada para modificar a su arbitrio, durante la fase de ejecución del contrato, las propias condiciones de licitación, sin que las disposiciones pertinentes aplicables contengan una habilitación expresa en tal sentido, los términos de la adjudicación del contrato, tal como se estipularon inicialmente, resultarían desnaturalizados. Por ello el Tribunal concluye que la aplicación de los principios de igualdad y transparencia no cesa con la adjudicación del contrato, sino que su vigencia se extiende a todo el ciclo contractual. En definitiva, "a falta de disposición expresa a tal efecto en el anuncio de licitación, se prohíbe a la entidad adjudicadora modificar, en cualquier fase del procedimiento, las condiciones de licitación, so pena de vulnerar el principio de igualdad de trato entre todos los licitadores y el principio de transparencia".

Posteriormente, en la sentencia de 19 de junio de 2008, Pressetext, asunto C-454/06, el Tribunal de Justicia tiene ocasión de aclarar y sistematizar cuándo una modificación contractual contraviene el derecho de la Unión Europea. En efecto, las modificaciones de las disposiciones de un contrato público efectuadas durante su vigencia constituyen una nueva adjudicación cuando "presentan características sustancialmente diferentes de las del contrato inicial y, por consiguiente, ponen de relieve la voluntad de las partes de volver a negociar los aspectos esenciales del contrato".

Y en la propia sentencia se ejemplifican supuestos en los que existe una modificación sustancial del contrato. En primer lugar, la modificación de un contrato en vigor puede considerarse sustancial cuando introduce condiciones que, si hubieran figurado en el procedimiento de adjudicación inicial, habrían

14 Entre las implicaciones más elementales del principio de igualdad: no se puede admitir una proposición que no cumpla los requisitos del pliego de preinscripciones (STJUE de 22 de junio de 1993, Comisión/Dinamarca, C-243/89); ni modificar durante la licitación los criterios de adjudicación sin respetar suficientemente las obligaciones de transparencia (STJUE de 25 de abril de 1996, Comisión/Bélgica, C-87/94); ni eludir la aplicación de los requisitos técnicos, aunque se permita a todos los licitadores modularlos (STJUE de 5 de diciembre 2013, Comisión/Estonia, C-561/12). 
permitido la participación de otros licitadores aparte de los inicialmente admitidos o "habrían permitido seleccionar una oferta distinta de la inicialmente seleccionada"15. En segundo lugar, de una interpretación sistemática de las directivas se desprende que la ampliación del contrato "en gran medida", constituye una nueva adjudicación ya que, en estos supuestos, y en estrictas circunstancias, se permite emplear el procedimiento negociado sin publicidad. Como cláusula de cierre, constituye una modificación sustancial la alteración de cualquier elemento de la documentación contractual que hubiera hecho más atractiva la licitación.

Finalmente, supone asimismo el cambio de uno de los términos esenciales del contrato público la subrogación de una nueva parte contratante en el lugar de aquella a la que la entidad adjudicadora había adjudicado inicialmente el contrato, a menos que esta subrogación estuviera prevista en los términos del contrato inicial, por ejemplo, mediante una subcontrata.

Como puede fácilmente adivinarse, la clave de bóveda del sistema consiste en definir qué es "condición esencial de la contratación", lo que constituye un concepto jurídico indeterminado que se define necesariamente en función de cada caso concreto. De esta forma, incluso en contratos de la misma naturaleza, unas mismas condiciones pueden tener carácter esencial o no dependiendo del resto de las cláusulas que determinen el contenido obligacional del contrato ${ }^{16}$.

Al margen de estas dificultades interpretativas, el TJuE parece prescindir de las causas que motivan la modificación de lo pactado. De esta forma, en aplicación rígida de esta doctrina la posibilidad de reequilibrar el contrato ante una circunstancia externa es muy limitada, ya que es difícil que la solución que reclame esta circunstancia no afecte a las condiciones esenciales de la contratación -v.gr., el precio del contrato-. Así, en línea de principio, tanto si la modificación obedece a un mero acuerdo de voluntades entre las partes -en el caso Succhi di Frutta, a la conveniencia de cambiar la fruta que constituía el precio por otra más rentable-como si responde a un hecho imprevisible - v.gr., a un desabastecimiento real de determinada fruta, siguiendo el ejemplo-, los límites a la modificación del contrato serían los mismos.

Todo ello en cierto modo podía explicarse porque el derecho de la Unión Europea permitía en determinadas circunstancias imprevisible ampliar el objeto contractual mediante un procedimiento no competitivo. Así, los contratos complementarios al principal, siempre que fueran la consecuencia del acaecimiento de un hecho objetivamente imprevisible, podían tramitarse a través del procedimiento negociado sin publicidad, procedimiento que no tiene carácter

15 De esta forma, puede entenderse que constituye una alteración de los elementos esenciales de la contratación la modificación de las condiciones de solvencia o de los criterios que hubieran sido determinantes para la elección del adjudicatario (p. ej., precio, plazo de ejecución, etc.).

Hemos tenido ocasión de recopilar la jurisprudencia en GALLEGO (2015). 
competitivo $^{17}$. Es esta la regulación que se contenía igualmente en el ACP, que permitía la licitación restringida en estos $\operatorname{casos}^{18}$.

Para la utilización del procedimiento negociado en estos casos era precisa la concurrencia de dos requisitos insoslayables: que la nueva adjudicación del contrato derivase de la concurrencia de una circunstancia imprevisible, y que se tratase bien de obras o suministros ${ }^{19}$, bien de servicios ${ }^{20}$ complementarios e inseparables del contrato inicial. Además, el importe acumulado de los contratos adjudicados para obras o servicios complementarios no podría ser superior al 50\% del importe inicial.

En todo caso, en derecho español han existido grandes dificultades para deslindar los conceptos de "modificación contractual" y "contrato complementario". Dada la amplitud con la que se ha reconocido la posibilidad de alterar el contrato en los supuestos de riesgo imprevisible, era hasta cierto punto estéril el debate sobre el carácter complementario o no de determinadas obras, suministros y servicios, ya que podían reconducirse con facilidad a los supuestos de reequilibrio económico del contrato, no precisando así tramitación alguna de un nuevo procedimiento de licitación. Pero en todo caso, como destacó Horgué Baena (1997, p. 205), en realidad el concepto de prestación complementaria prevista en el derecho europeo abarcaba determinados supuestos que en derecho español se consideraban modificaciones contractuales $^{21}$. La jurisprudencia europea posterior ha confirmado la certeza

17 En la legislación española, por ejemplo, se dispone que en el procedimiento negociado la adjudicación recaerá en el licitador justificadamente elegido por el órgano de contratación, tras efectuar consultas con diversos candidatos y negociar las condiciones del contrato con uno o varios de ellos (art. 169 TRLCSP). Así, se dispone que en el procedimiento negociado será necesario solicitar ofertas, al menos a tres empresas capacitadas para la realización del objeto del contrato, siempre que ello sea posible.

18 Según el artículo XV de la versión original del Acuerdo, no será necesario aplicar las disposiciones de los artículos VII a XIV, que regulan las licitaciones públicas y selectivas, "cuando, debido a circunstancias imprevisibles, para completar los servicios de construcción descritos en el pliego de condiciones original resulten necesarios servicios de construcción adicionales no incluidos en el contrato inicial pero comprendidos en los objetivos de dicho pliego y la entidad necesite adjudicar los contratos de los servicios adicionales de construcción al contratista que preste los servicios de construcción en cuestión, debido a que la separación de los servicios de construcción adicionales del contrato inicial sería difícil por razones técnicas o económicas y originaría importantes trastornos a la entidad. Sin embargo, el valor total de los contratos adjudicados para los servicios adicionales de construcción no podrá ser superior al 50 por ciento del importe del contrato principal".

19 Ver art. 31.4 a) Directiva 2004/18/CE. El artículo 61 de la directiva extendía este mismo régimen a la adjudicación de obras complementarias al concesionario.

20 Ver art. 31.2 b) Directiva 2004/18/CE.

21 Como es sabido, el artículo 153 del Decreto 3410/1975 establecía que las obras accesorias o complementarias no incluidas en el proyecto durante el curso de la obra principal que la Administración estimara conveniente ejecutar, deberían ser objeto de contrato independiente, salvo aquéllas cuyo importe no excediera del 20\% del precio de contrato, cuya 
de esta apreciación. Las ampliaciones del objeto contractual tienen carácter de prestación complementaria (STJUE de 29 de abril de 2010). También las alteraciones en el proyecto de las obras para introducir servicios, suministros y obras no previstos inicialmente (STGUE de 31 de enero de 2013, España c. Comisión, T-235/11) 22. Por tanto, en estos casos estaba proscrita la modificación del contrato y sólo era posible adjudicar un nuevo contrato al adjudicatario si concurrieren las estrictas circunstancias ya señaladas, lo que no siempre ha sucedido en la práctica española.

\section{LA MODIFICACIÓN DEL CONTRATO ANTE CIRCUNSTANCIAS IMPREVISIBLES EN LAS DIRECTIVAS 23/2014/UE SOBRE CONCESIONES Y 24/2014/UE SOBRE CONTRATACIÓN PÚBLICA}

\subsection{El discutido reconocimiento del principio de reequilibrio económico del contrato en la Directiva sobre concesiones}

El principio de reequilibrio económico del contrato ha nacido dogmáticamente ligado a los contratos de concesión, por lo que es fácil deducir que la severa interpretación descrita plantea sus mayores dificultades prácticas cuando de estos contratos se trata.

La propia Comisión Europea advirtió que la rígida aplicación de los criterios jurisprudenciales sobre la modificación de los contratos podría presentar disfunciones cuando se trata de contratos complejos y de larga duración. Así, del "Libro Verde sobre la colaboración público-privada y el Derecho comunitario en materia de concesiones" ${ }^{\prime \prime 23}$ parece desprenderse que cuando concurriese una circunstancia imprevisible o una razón imperiosa de interés general podía flexibilizarse el requisito de que la modificación no afectase a las condiciones esenciales de la licitación. De hecho, en dicho Libro Verde se somete a consulta la posibilidad de aclarar a escala comunitaria determinados aspectos correspondientes al marco contractual de las operaciones de CPP. Y

ejecución podría confiarse al contratista de la principal. De esta forma, por debajo de este importe, el contrato complementario podía revestirse de mera modificación del contrato inicial.

22 La sentencia categóricamente afirma que, "contrariamente a lo que sostiene el Reino de España, cabe considerar que el artículo 20, apartado 2, letras e) y f), de la Directiva 93/38 se aplica a las modificaciones de contratos públicos acordadas durante su fase de ejecución". La sentencia enjuicia la reducción de la ayuda financiera inicialmente acordada por el Fondo de Cohesión a cinco proyectos relativos a cinco líneas ferroviarias del AVE y ha sido anulada por la STJUE de 4 de septiembre de 2014, C-197/13 P, España contra Comisión, ya que la Comisión no respetó el plazo legal para adoptar una decisión de corrección financiera. En todo caso, el TJuE no ha entrado en los motivos de fondo, por lo que entendemos que la doctrina del TJUE sigue siendo en este punto totalmente válida.

Libro Verde de 30 de abril de 2004, COM (2004) 327 (apdos. 4 y 50). 
entre las partes interesadas se alcanza un grado de consenso amplio en relación con la necesidad de ajustar a lo largo del tiempo las fórmulas de contratación público-privada contractual ${ }^{24}$.

Antes de la formulación de las propuestas de nuevas directivas, en el Libro Verde sobre "La modernización de la política de contratación pública de la UE" de $2011^{[25]}$, la Comisión reconoce que los cambios posteriores a la licitación que tienen una repercusión en el propio contrato o en su ejecución constituían "una cuestión particularmente compleja". Por ello, la Comisión sometió a consulta la necesidad de una aclaración jurídica al nivel de la Unión Europea para establecer las condiciones en las que la modificación de un contrato exige un nuevo procedimiento de adjudicación. El documento de síntesis de las respuestas al Libro Verde ${ }^{26}$ refleja que una mayoría de repuestas procedentes de todos los grupos interesados apoyaban la introducción de previsiones que definiesen y clarificasen las condiciones y consecuencias legales de una modificación esencial de un contrato durante su ejecución ${ }^{27}$.

De esta forma, tanto en la memoria explicativa la propuesta de Directiva sobre contratación pública ${ }^{28}$ como en la propuesta de Directiva sobre concesiones $^{29}$ se admite cuanto sigue:

24 Ver pp. 20 y 21 del Documento de Trabajo de la Comisión "Report on the public consultation on the Green Paper on Public-Private Partnerships and Community Law on Public Contracts and Concessions", de 3 de mayo de 2005, SEC (2005) 629.

Posteriormente, en el cuestionario incluido en la iniciativa europea sobre concesiones [disponible en: http://www.minhap.gob.es/gl-ES/Servicios/Contratacion/Junta\%20Consultiva $\% 20 \mathrm{de} \% 20$ Contratacion\%20Administrativa/Paginas/nomenclaturas.aspx] se consulta a las partes interesadas si consideran que el marco legal actual relativo a las modificaciones de concesiones, como opina el Tribunal de Justicia de la Unión Europea en sus sentencias Succhi di Frutta, Pressetext, Acoset y Wall AG8, queda suficientemente claro y permite tener en cuenta la naturaleza evolutiva de las concesiones.

25 Libro Verde sobre "La modernización de la política de contratación pública de la UE. Hacia un mercado europeo de la contratación pública más eficiente", Bruselas, 27-1-2011, COM (2011) 15 final.

26 Green Paper on the Modernisation of Eu Public Procurement Policy. Towards a more efficient European Procurement Market Synthesis of Replies. Disponible en: http://ec.europa.eu/ internal_market/consultations/docs/2011/public_procurement/synthesis_document_en.pdf

27 Además, en el Libro Verde se abordaban de forma específica las cuestiones relativas a los cambios que afecten al contratista, tales como la sustitución del contratista por otra entidad legal, pero también cambios en su estatus o propiedad. Sin embargo, solo una minoría de las partes interesadas consideró que existía un valor añadido en la incorporación de reglas sobre los cambios que afecta al licitador seleccionado durante la ejecución del contrato.

28 Propuesta de Directiva relativa a la contratación pública, COM (2011) 896 final, de 20 de diciembre de 2011.

29 Propuesta de Directiva relativa a la adjudicación de contratos de concesión, COM (2011) 897 final, de 20 de diciembre de 2011. 
La modificación de los contratos durante su periodo de vigencia se ha convertido en un aspecto cada vez más importante y problemático para las partes interesadas. En una disposición específica sobre modificación de las concesiones se recogen las soluciones básicas desarrolladas por la jurisprudencia y se ofrece una solución pragmática para hacer frente a las circunstancias imprevistas que hagan necesaria la modificación de una concesión durante el periodo de vigencia.

En definitiva, las propuestas ${ }^{30}$ buscan introducir cierto grado de flexibilidad para adaptar el contrato a esas circunstancias externas imprevisibles sin necesidad de un nuevo procedimiento de contratación. Resulta destacable que en las propuestas originales de la Comisión el régimen jurídico de las modificaciones contractuales era prácticamente idéntico, independientemente de que se tratase de un contrato público de obras, suministros o servicios, o de una concesión.

No obstante, el Parlamento europeo trató de establecer un régimen jurídico radicalmente diferente, según se tratase de uno u otro caso, de forma que si bien se mantenía con carácter restrictivo la posibilidad de modificar el contrato en la propuesta sobre contratación pública -que afecta, como se conoce bien, a obras, suministros y servicios-, se pretendió reconocer con un carácter mucho más flexible el ius variandi en el ámbito de las modificaciones concesionales. Así, en el Informe del Parlamento sobre la Directiva de concesiones se alteraba la redacción del primer apartado del entonces artículo 42, de forma que el precepto comenzaba estableciendo como principio general que "una concesión vigente podrá ser modificada mediante una adición al contrato salvo si las modificaciones son sustanciales" ${ }^{\prime 31}$. Además, en uno de los considerandos se añadía: "toda concesión vigente puede ser modificada mediante un acuerdo adicional, de conformidad con la presente Directiva" 32

Pero esta propuesta no halló el apoyo ni del Consejo ni de la Comisión europea. Los considerandos de la Directiva de concesiones -al igual que el relativo a la Directiva sobre contratación pública- no recogen la declaración de principios propuesta por el Parlamento, manteniendo en cambio el reenvío a la jurisprudencia del Tribunal de Justicia de la Unión Europea como parámetro interpretativo en su formulación clásica. De esta forma, el derecho europeo no reconoce en modo alguno un supuesto principio de mutabilidad de la concesión.

30 Ver art. 42 de la Propuesta de Directiva sobre concesiones y art. 72 de la Propuesta de Directiva sobre contratación pública.

31 Ver enmienda 224 del proyecto de Resolución legislativa del Parlamento Europeo sobre la propuesta de Directiva del Parlamento Europeo y del Consejo relativa a la adjudicación de contratos de concesión, de 1 de febrero de 2013. La justificación de la enmienda era totalmente elocuente en este sentido. Literalmente se afirmaba: "Introducción de un nuevo apartado para aclarar el artículo especificando que se puede modificar una concesión vigente (principio general) excepto si las modificaciones son sustanciales (exclusiones)".

Ver enmienda 51. 
Con ello, la regulación del riesgo imprevisible en el ámbito de los contratos de obras, suministros y servicios, es paralela a la disciplina introducida en la Directiva sobre concesiones, lo que a priori puede resultar sorprendente, habida cuenta de que sería este uno de los ámbitos propios de una regulación específica de las concesiones ${ }^{33}$. Sin embargo, en mi opinión, en contra de lo que han defendido otros autores ${ }^{34}$, no puede afirmarse que la Directiva sobre concesiones desconozca el principio del mantenimiento económico de la concesión. Más bien lo acota. Esta interpretación, a mi juicio, estaría reforzada por el considerando $18^{[35]}$ y el artículo $\left.5 \mathrm{~b}\right)^{36}$, que insisten en que la transferencia del riesgo se realiza en condiciones "normales" de funcionamiento. Por lo que puede deducirse, a contrario, que si una circunstancia imprevisible quiebra la "normalidad" de las condiciones de explotación de la obra o servicio, las consecuencias del desequilibrio dejan de situarse exclusivamente en la órbita del concesionario.

Así pues, se estima, sin perjuicio de las modulaciones que se pueden introducir en los ordenamientos dependiendo de los distintos tipos contractuales, que será probablemente la jurisprudencia la que adapte el principio del mantenimiento del equilibrio económico del contrato a la complejidad y mayor duración de las concesiones.

Como destaca la autora, la omisión debe reputarse consciente a la luz de lo manifestado al respecto por el Consejo de la Unión Europea. Y es que, efectivamente, en la propuesta de Directiva relativa a la adjudicación de contratos de concesión, orientación general, de 26 de noviembre de 2012, punto n. ${ }^{\circ}$ 10, el Consejo señalaba que "el mantenimiento puede lograrse plenamente mediante la aplicación de los apartados 5 y 6 del artículo 42 en relación con posibles modificaciones bien previstas en el contrato o bien cuya necesidad se derive de circunstancias imprevisibles".

35 Según el mismo, "las dificultades relacionadas con la interpretación de los conceptos de concesión y de contrato público han generado una inseguridad jurídica continua para las partes interesadas y han dado lugar a numerosas sentencias del Tribunal de Justicia de la Unión Europea. Por lo tanto, debe aclararse la definición de 'concesión', en particular haciendo referencia al concepto de riesgo operacional. La característica principal de una concesión, el derecho de explotar las obras o los servicios, implica siempre la transferencia al concesionario de un riesgo operacional de carácter económico que supone la posibilidad de que no recupere las inversiones realizadas ni cubra los costes que haya sufragado para explotar las obras o los servicios adjudicados en condiciones normales de funcionamiento, si bien parte del riesgo siga asumiéndolo el poder o entidad adjudicado" (cursiva nuestra).

Dicho precepto establece: "La adjudicación de las concesiones de obras o servicios implicará la transferencia al concesionario de un riesgo operacional en la explotación de dichas obras o servicios abarcando el riesgo de demanda o el de suministro, o ambos. Se considerará que el concesionario asume un riesgo operacional cuando no esté garantizado que, en condiciones normales de funcionamiento, vaya a recuperar las inversiones realizadas ni a cubrir los costes que haya contraído para explotar las obras o los servicios que sean objeto de la concesión" (cursiva nuestra). 


\subsection{Los supuestos habilitantes de la modificación del contrato: generalidades}

Una modificación sustancial de un contrato durante su vigencia requiere una nueva adjudicación. Así se desprendía de la jurisprudencia del TJuE y este principio general ha sido puntualmente codificado en las nuevas directivas. El mandato es inequívoco: "será prescriptivo iniciar un nuevo procedimiento de contratación de conformidad con la presente Directiva para introducir en las disposiciones de un contrato público o un acuerdo marco, durante su período de vigencia, modificaciones distintas de las previstas en los apartados 1 y $2^{\prime \prime 37}$.

De esta forma, toda modificación sustancial de las disposiciones de un contrato público durante su periodo de vigencia será considerada una nueva adjudicación a efectos de lo dispuesto en la directiva y conllevará un nuevo procedimiento de adjudicación regido por la misma, salvo en los supuestos tasados y de interpretación restrictiva que las propias directivas establecen. Es posible sistematizar los distintos tipos de modificaciones y sus efectos atendiendo a la siguiente clasificación:

a) "modificaciones que no tienen carácter sustanciales", modificaciones a las que las directivas no imponen límites expresos ${ }^{38}$;

b) modificaciones que afectan condiciones sustanciales de la licitación -sin afectar la naturaleza global del contrato-, que son admisibles siempre que: $a^{\prime}$ ) estén previstas en la documentación contractual ${ }_{i} b^{\prime}$ ) obedezcan a circunstancias imprevisibles ${ }_{i} \mathrm{c}^{\prime}$ ) sean necesarias e inseparables técnica o económicamente del contrato inicial, o d') no alcancen determinada cuantía,

c) modificaciones que alteran la naturaleza global del contrato, cuya incorporación al contrato requiere en todo caso el inicio de un nuevo procedimiento de licitación.

Como ya hemos señalado, en la doctrina del Tribunal de Justicia la aparición de una circunstancia imprevisible no permitía modificar las condiciones esenciales de la licitación. El poder adjudicador podía, eventualmente, adjudicar un contrato complementario a través de un procedimiento negociado sin publicidad. Sin embargo, la posibilidad de modificar elementos sustanciales del contrato cuando un elemento externo lo afectaba había sido sugerida por autores como Arrowsmith (2005, p. 288), Harten y Liljenbol (2013, p. 57) o Poulsen (2012, p. 173). La nueva directiva, según acabamos de ver, recoge ex- 
presamente el acaecimiento de una circunstancia imprevisible como supuesto de modificación del contrato.

La decisión del legislador de la Unión Europea de afrontar la regulación de las modificaciones contractuales ante el cambio de circunstancias que rodearon la licitación merece una crítica positiva. Por un lado, porque el mecanismo previsto en la Directiva 2004/18/CE era claramente insuficiente ${ }^{39}$. Por otro, porque la tendencia a la modulación de los efectos del contrato cuando acaece un elemento imprevisible no es una característica exclusiva de la contratación administrativa. En el ámbito del derecho privado se ha reconocido que la obligatoriedad del contrato no debe extenderse más allá de lo expresamente pactado y al riesgo que debió ser asumido por las partes ${ }^{40}$. Y aunque la respuesta que dan los distintos ordenamientos ante este tipo de supuestos es divergente $^{41}$, entre las dos alternativas disponibles -modificación del contrato

39 En cierto modo, como señaló Horgué BAENA (1997, pp. 205-211), la utilización del procedimiento negociado sin publicidad para hacer frente a circunstancias externas podría resultar un mecanismo excesivamente tortuoso para la adaptación del contrato, siendo en realidad idénticos los efectos prácticos en comparación con los propios de la modificación del contrato. Porque hay que tener en cuenta que la posibilidad de utilizar el procedimiento negociado sólo estaba prevista cuando se tratara de prestaciones adicionales y debía en todo caso tratarse bien de obras bien de servicios estrictamente necesarios, bien de los únicos suministros técnicamente compatibles. Pero en ocasiones era conveniente modificar otros aspectos, tales como el precio.

40 Ver CASTIÑ̃eIRA JéreZ (2012). Bien es verdad que el autor considera que la jurisprudencia civil española debería adoptar un enfoque menos estricto y más cercano al mantenido en el ámbito de la contratación administrativa.

En todo caso, el artículo 1593 CC establece que "el arquitecto o contratista que se encargue por un ajuste alzado de la construcción de un edificio en vista de un plano convenido con el propietario del suelo no puede pedir aumento de precio aunque se haya aumentado el de los jornales o materiales...". Pues bien, en la aplicación de este precepto, aunque en nuestro derecho no tenemos, como en otros ordenamientos, una norma general de alteración sobrevenida de las prestaciones por causas extraordinarias no previstas o previsibles, puede ser de aplicación la cláusula de la excesiva onerosidad sobrevenida o la alteración de la base objetiva del contrato, más que la cláusula rebus sic stantibus, cuyos presupuestos son más extraordinarios y, por tanto, más restrictivos. Ver Albiez Dohrmann (2013, p. 11269).

En relación con las diferencias entre derecho público y derecho privado en la ejecución de los contratos, ver Medina AlCOZ (2014, pp. 77 ss.).

41 Desde una perspectiva de derecho privado comparado, dentro de las diferentes iniciativas de unificación internacional en materia de contratos es especialmente interesante el proyecto desarrollado por la Comisión sobre Derecho Contractual Europeo. Pues bien, dentro de los Principios de Derecho Europeo de los Contratos elaborados en el seno de esta Comisión, el artículo 6:111 regula el "Cambio de circunstancias" con el siguiente tenor: "(1) Las partes deben cumplir con sus obligaciones, aun cuando les resulten más onerosas como consecuencia de un aumento en los costes de la ejecución o por una disminución del valor de la contraprestación que se recibe. (2) Sin embargo, las partes tienen la obligación de negociar una adaptación de dicho contrato o de poner fin al mismo si el cumplimiento del contrato resulta excesivamente gravoso debido a un cambio de las circunstancias, siempre que: (a) Dicho cambio de circunstancias haya sobrevenido en un momento posterior a la 
o resolución- el derecho europeo de la contratación pública opta por imponer límites a los derechos nacionales cuando se prevea la utilización de la primera. Y si bien Santamaría Pastor (2013, p. 35) llama la atención sobre la paradójica introducción de este tipo de normas en la contratación pública ante la falta de unificación de las reglas de fondo que, en el derecho privado, regulan los contratos paralelos, lo cierto es que en el ámbito de la contratación pública esta regulación es una consecuencia de la necesidad de preservar los principios de igualdad y transparencia en el ámbito de la ejecución.

En todo caso, la posibilidad de modificar el contrato por causas imprevisibles está sometida tanto a límites formales como materiales. Desde el punto de vista formal, se exige la publicación de un anuncio en el Diario Oficial de la Unión Europea. Y desde el punto de vista material, se dispone que el incremento del precio resultante no podrá ser superior al 50\% del importe inicial y la modificación no puede alterar la naturaleza global del contrato. Estos dos últimos condicionantes serán analizados en el epígrafe siguiente.

\subsection{La caracterización del "riesgo imprevisible" en el derecho de la Unión Europea}

El supuesto habilitante para modificar el contrato es el acaecimiento de circunstancias que un poder adjudicador diligente no hubiera podido prever. De esta forma, la Directiva 24/2014/UE permite introducir cierto grado de flexibilidad para adaptar el contrato a nuevas circunstancias exteriores que no se podían prever aunque el poder adjudicador hubiera preparado con razonable diligencia la adjudicación inicial ${ }^{42}$.

Pues bien, para determinar el carácter previsible o no de la circunstancia es preciso tener en cuenta los medios a disposición del poder adjudicador, la naturaleza y las características del proyecto concreto, las buenas prácticas en el ámbito de que se trate y la necesidad de garantizar una relación adecuada entre los recursos empleados en la preparación de la adjudicación y su valor previsible ${ }^{43}$. Se impone, en todo caso, una aproximación fuertemente restric-

conclusión del contrato. (b) En términos razonables, en el momento de la conclusión del contrato no hubiera podido preverse ni tenerse en consideración el cambio acaecido. (c) A la parte afectada, en virtud del contrato, no se le pueda exigir que cargue con el riesgo de un cambio tal de circunstancias. (3) Si en un plazo razonable las partes no alcanzan un acuerdo al respecto, el juez o tribunal podrá: (a) Poner fin al contrato en los términos y fecha que considere adecuado. (b) $\mathrm{O}$ adaptarlo, de manera que las pérdidas y ganancias resultantes de ese cambio de circunstancias se distribuyan entre las partes de forma equitativa y justa".

42 Ver Considerando 109 de la Directiva sobre contratación pública y considerando 76 de la Directiva sobre concesiones.

43 Ver Considerando 109 de la Directiva sobre contratación pública y considerando 76 de la Directiva sobre concesiones. 
tiva del concepto de imprevisibilidad. En ese sentido, es una pauta orientativa la jurisprudencia del TJuE elaborada en torno a la aplicación del artículo 31.1 c) de la Directiva 2004/18 CE y preceptos concordantes ${ }^{44}$. Por todo ello, interesa destacar que el concepto de "circunstancia imprevista" que permite la utilización del procedimiento negociado sin publicidad se ha sometido a dos importantes límites: la interpretación estricta y la carga de la prueba.

Así, la imprevisibilidad es "un parámetro objetivo", de forma que "únicamente la imprevisibilidad objetiva de los acontecimientos lo libera [al poder adjudicador] de la obligación de adoptar precauciones para observar las disposiciones de la Directiva" ${ }^{\prime \prime 5}$. A modo de ejemplo, no puede calificarse como imprevisible algo que ya podía ser conocido de antemano, como es el incremento del número de alumnos en una universidad pública ${ }^{46}$. Tampoco puede justificarse como circunstancia imprevisible el aumento de un riesgo que ya era conocido ${ }^{47}$.

Por su parte, la ya citada STGUE de 31 de enero de 2013 es una buena muestra del canon estricto con el que ha de valorarse en cada caso el concepto de imprevisibilidad ${ }^{48}$, así como del hecho de que la carga de la prueba del carácter imprevisible del hecho corresponde a quien lo alega. De esta forma, por ejemplo, no se puede considerar imprevisible el incremento de una determinada población, si este incremento se ha mantenido constante y no se ha producido un crecimiento de carácter excepcional (apdo. $81{ }^{49}$; tampoco puede considerarse una circunstancia imprevisible la modificación del planeamiento urbanístico, cuando el poder adjudicador no ha conseguido un consenso previo sobre las soluciones proyectadas con los municipios afectados (apdo. 90). Finalmente, no constituye una circunstancia imprevisible el hecho de que exista una diferencia con las condiciones geotécnicas reales si no se han realizado estudios previos del suelo (apdo. 107).

Ver art. 7, apdo. 3, lit. c) de la Directiva 93/37/CEE; art. 6, apdo. 3, lit. d) de la Directiva 93/36/CEE, y art. 11, apdo. 3, lit. d) de la Directiva 92/50/CEE.

STJUE de 10 de marzo de 1992, Comisión/España, C-24/91.

Ibíd.

STJuE de 2 de agosto de 1993, Comisión/Italia, C-107/92.

En este mismo sentido se ha pronunciado el IJCCA Estado 5/10, de 23 de julio de 2010, según el cual "para la determinación de si una circunstancia acaecida con posterioridad a la adjudicación de un contrato y que afecta a la ejecución del mismo es o no imprevista deben tenerse en cuenta dos ideas básicas. De una parte que tal circunstancia, de conformidad con las reglas del criterio humano hubiera podido o debido ser prevista y, en segundo lugar, que la falta de previsión no se haya debido a negligencia en el modo de proceder de los órganos que intervinieron en la preparación del contrato".

9 Ver igualmente STJUE 2 de agosto de 1993, Comisión/Italia, C-107/92. 


\subsection{El límite al restablecimiento: límites cuantitativos y la preservación de la naturaleza global de la contratación}

Aun cuando concurra a un hecho imprevisible, la modificación del contrato debe respetar dos límites: no sobrepasar determinados umbrales cuantitativos y la preservación de la naturaleza global del contrato.

En primer lugar, el incremento del precio resultante de la modificación no podrá ser superior al 50\% del importe inicial. Ahora bien, "en el caso de que se introduzcan varias modificaciones sucesivas, esta limitación se aplicará al valor de cada una de las modificaciones. Estas modificaciones consecutivas no deberán tener por objeto eludir las disposiciones de la presente Directiva". Esta generosa regulación de los límites cuantitativos es, en mi opinión, uno de los aspectos más criticables de la regulación de este supuesto de modificación contractual en las nuevas directivas y supone un elemento muy destacado de innovación respecto de la Directiva 2014/18/CE ${ }^{50}$. Sin embargo, no creo que daba subestimarse la importancia cualitativa de las modificaciones a la hora de determinar si es admisible el modificado, en virtud de la interpretación del límite infranqueable al respeto de "naturaleza global de la contratación". Difícilmente podrá considerarse que, en el caso de que de los importes acumulados de los modificados lleguen a superar el precio del contrato inicial, se está ante el contrato originario. También podrá dudarse de si el resultado hubiera sido el mismo si el resto de licitadores hubieran tenido oportunidad de conocer la entidad de las alteraciones que sufriría el contrato.

En segundo lugar, la modificación no puede alterar "la naturaleza global del contrato". Se plantea aquí el caballo de batalla de la nueva regulación, pues no es del todo evidente qué sea este concepto. Las dudas interpretativas surgirán porque los parámetros para deslindar qué condiciones esenciales alteran la naturaleza global del contrato no son ni mucho menos evidentes. Puesto que la definición de "condiciones esenciales del contrato" y la de "naturaleza global" tienen como referente un elemento común: su eventual "influencia en el resultado del procedimiento" ${ }^{\prime \prime}$. En todo caso, se altera la naturaleza global de la contratación, "por ejemplo, si se sustituyen las obras, los suministros o los servicios que se van a adquirir por otros diferentes", o se modifica de manera

50 En el artículo 31.4 de Directiva 2004/18/CE el importe acumulado de los contratos adjudicados para obras o servicios complementarios no podrá ser superior al 50\% del contrato inicial. Esta misma regulación es la que se contenía en la propuesta de Directiva sobre contratación pública.

51 En relación con el concepto de "modificación no sustancial", ver art. 72.5 a) Directiva 2014/24/UE y considerando 107 de la Directiva 2014/24/UE, y art. 41.5. a) y considerando 75 de la Directiva 2014/23/ue. En relación con la caracterización de la "naturaleza global del contrato", ver considerando 109 de la Directiva 2014/24/UE y considerando 76 de la Directiva 2014/23/UE. 
fundamental el "tipo de contratación" o "el tipo de la concesión" 52 . Ello sucedería, como ejemplifica la propia Comisión ${ }^{53}$, si el poder adjudicador decide adquirir en propiedad la flota de vehículos en lugar de realizar la operación de arrendamiento financiero (leasing) inicialmente licitada, o si se renuncia a la naturaleza orgánica de los alimentos que fueron objeto de un contrato de suministro.

En mi opinión, es preciso tener en cuenta que el criterio de la naturaleza global no hace referencia exactamente a la naturaleza del contrato concluido, sino a un concepto más amplio, el de las características esenciales del procedimiento de contratación que se ha realizado previamente ${ }^{54}$. En otros términos, se alterará la naturaleza global de la contratación si se introducen variaciones en aquellos elementos que de modo más decisivo han condicionado el desarrollo del procedimiento de contratación, desde la perspectiva tanto del número de las ofertas recibidas como de su contenido. Y ello sucederá, ya sea mediante la alteración del objeto del contrato, ya sea cuando se rebasen determinados límites cuantitativos, y ya sea también, aunque expresamente no se refleje en las directivas, si se altera el equilibrio del contrato a favor del contratista, pues este equilibrio es obviamente parámetro decisivo del desenvolvimiento del procedimiento de licitación. Así, la naturaleza global del contrato no equivale a las condiciones esenciales de la contratación, ya que es un concepto más reducido. En otros términos, aunque todo lo que afecta a la naturaleza global del contrato afecta a sus condiciones esenciales, sólo algunas de estas condiciones esenciales configuran la naturaleza global, límite este último en todo caso inquebrantable.

Por tanto se considera que no resulta criticable que se haya desligado la modificación ante una circunstancia imprevisible del carácter esencial o no de la modificación contractual. Porque habrá determinadas circunstancias en las que una modificación tenga carácter sustancial, pero que, por encuadrarse dentro de determinados límites, pueda admitirse como medida del reequilibrio económico siempre que se haya verificado un riesgo imprevisible. Sirva como ejemplo la necesidad de incrementar el precio de un contrato de obras ante un desmesurado aumento de los precios de las materias primas ${ }^{55}$, aumento que

52 Considerando 109 de la Directiva 2014/24/UE y considerando 76 de la Directiva 2014/23/ UE.

53 Ver el documento del Consejo 11266/12, de 14 de junio de 2012, que incluye en un anexo un documento elaborado por la Comisión.

54 La primera acepción de "naturaleza" del Diccionario de la Real Academia de la Lengua Española es "esencia y propiedad característica de cada ser".

55 Se trata de un supuesto que se ha abordado de manera recurrente en nuestra jurisprudencia, cuya doctrina tuve oportunidad de sistematizar en el trabajo "Contrato administrativo de obras y doctrina del riesgo imprevisible", publicado en los números 98 y 99 de Contratación Administrativa Práctica. Bajo esta misma perspectiva debe analizarse la ampliación del plazo concesional como medida de restablecimiento del equilibrio económico 
será admisible si no se altera la naturaleza global del contrato ni se sobrepasan determinados límites cuantitativos.

En definitiva, si un modificado afecta las condiciones esenciales de la contratación habrá de prescindirse de las causas que lo motivan. Una vez que un modificado se califique como esencial -dicho en otros términos, se considere que afecta las condiciones esenciales de la contratación-, aún existirá margen para considerarlo adecuado a derecho de la Unión Europea si obedece a causas tasadas y cualificadas y no vulnera el límite infranqueable de la naturaleza global del contrato. Por ejemplo, la disminución del canon pactado en el ámbito de un contrato de concesión supondrá la alteración de una condición esencial y por tanto constituye una modificación en principio proscrita. Sin embargo, si con ello se pretende preservar la continuidad del contrato ante el acaecimiento de una circunstancia objetivamente imprevisible, y no se altera la naturaleza global del contrato, la modificación puede resultar admisible ${ }^{56}$.

Pero en todo caso baste recordar, sin ánimo de exhaustividad, que no podrá alterarse el objeto del contrato o concesión ${ }^{57}$, ni se podrá incorporar prestaciones diferentes a las inicialmente pactadas ${ }^{58}$. Como tampoco afectar un elemento decisivo en la configuración de las ofertas de los licitadores ${ }^{59}$.

del contrato, reconocida dentro de un severo límite temporal del $10 \%$ en el artículo 282 TRLCSP. Hemos tenido oportunidad de profundizar sobre esta cuestión en GALLEGO CÓRCOLES, I. (2012).

56 Sirva como ejemplo el supuesto de la ya citada STS de 30 de junio de 2014 (Sala de lo Civil rec. 2250/2012), que otorga la rebaja del canon solicitada por la demandante en aplicación de la cláusula rebus sic stantibus. En el supuesto, se trataba de un contrato de explotación de publicidad incluida en las marquesinas de la parada de autobuses. El contratista consigue probar que la inversión en publicidad en el sector del transporte sufre un descenso en el año 2009 de un $67,62 \%$ y, debido a esta causa, el Tribunal accede a modificar el canon pactado. En este ejemplo es evidente que se afecta una condición esencial del contrato. Sin embargo, no se afecta su naturaleza global.

57 STS de Andalucía de 30 de julio de 2003 (rec. 2717/1997), en la que se declara contraria a derecho la modificación contractual que implicaba el traslado de la concesión de un puesto de mercado público a otro mercado.

58 Sirva como expresivo ejemplo el supuesto resuelto por la STSJ de Canarias de 1 de marzo de 1999. En el evento allí enjuiciado, no sólo se modifica el plazo de duración del contrato de concesión de servicio de abastecimiento de agua, sino que, además, el concesionario se compromete a realizar importantes inversiones a las que no venía obligado según el pliego de condiciones técnicas y económico-administrativas.

59 A modo de ilustración puede servir de guía el supuesto que resuelve el IJCCA Aragón 4/2012, de 1 de febrero. El caso versa sobre un contrato de obra, en el que un ayuntamiento se comprometía a abonar parte del precio mediante la entrega de suelo municipal. En fase de ejecución, se pretende el abono de la integridad del precio en metálico, ya que el contratista ha entrado en situación de concurso de acreedores. Con buen criterio la Junta considera que "las propias circunstancias del contrato pactado en el que el precio a abonar en especie es el $37 \%$ del precio total, ascendiendo a la importante cantidad de $1.409 .884,14 €$, revelan que la forma de pago fue un aspecto decisivo en la licitación, ya que cualquier empresario 
En definitiva, sólo es posible introducir modificaciones de los elementos esenciales del contrato cuando concurra alguna de las causas cualificadas que de forma tasada contempla el precepto. De esta forma, el legislador europeo, ante determinadas circunstancias, sacrifica el principio de concurrencia en aras de la consecución de otros intereses públicos, como es la propia continuidad del contrato. Por ello, la interpretación de los supuestos en los que se permite este tipo de modificaciones ha de ser necesariamente restrictiva. Y las modificaciones introducidas han de guiarse por el principio de proporcionalidad ${ }^{60}$.

\section{5. ¿Puede incluirse el factum principis en el concepto de "circunstancia imprevisible" previsto en las directivas?}

Las consideraciones anteriores permiten afirmar que la doctrina del riesgo imprevisible tiene perfecto acomodo en el nuevo derecho de la contratación pública. Las dudas surgen, sin embargo, respecto del encaje del factum principis en el esquema conceptual de las nuevas directivas sobre contratación pública. Porque los cambios en el marco regulatorio o derivados del control de aquellos riesgos que se sitúan en la órbita de la Administración pueden considerarse ajenos a la regulación europea del riesgo imprevisible ${ }^{61}$, ya que siempre se podrá argumentar que el poder adjudicador no fue lo suficientemente diligente a

interesado en ella debió valorar que la financiación de una gran parte de la obra la asumía directamente, quedando a expensas de la transmisión del inmueble municipal por parte del Ayuntamiento y a su posterior venta o puesta en valor para resarcirse de la inversión. Esta opción tenía frente al pago en efectivo unos riesgos como se aprecia de forma clara e inequívoca en este caso, y obviamente los mismos condicionaron las ofertas presentadas por los licitadores. Por lo tanto no es posible la modificación pretendida, por afectar de manera evidente a una condición esencial del contrato". En mi opinión, además, se pretendía afectar la naturaleza global del contrato, por lo que bajo ninguna circunstancia era posible acceder a lo solicitado por el contratista.

60 Según reiterada jurisprudencia, el principio de proporcionalidad forma parte de los principios generales del derecho europeo y exige que las medidas de que se trate no rebasen los límites de lo que resulta apropiado para el logro de los objetivos perseguidos, entendiéndose que, cuando exista la posibilidad de optar por varias medidas adecuadas, deberá recurrirse a la menos onerosa. Sobre las implicaciones de este principio en el ámbito de la contratación pública, ver MORENO MOLINA (2007, p. 66). Este principio se ha reconocido en el artículo 107.2 TRLCSP.

61 Para SÁnCHEZ GRAellS (2012, p. 11) se puede argumentar fácilmente que los cambios en el marco regulatorio pueden ser previstos en todo caso por una Administración diligente, lo que impide aplicar la posibilidad de modificar el contrato para restablecer el equilibrio económico de la concesión. Como explica el autor, los poderes adjudicadores retendrán, en muchos casos, poderes importantes para tomar decisiones importantes que afecten la demanda. Por ejemplo, se pueden adoptar medidas para promover el uso de los servicios o alterar la importancia de la infraestructura. En estos casos parecería apropiado ofrecer a los concesionarios garantías de que sus inversiones no se verán materialmente perjudicadas por las decisiones de los poderes adjudicadores, ya que luce apropiado que los concesionarios asuman todos los riegos que pueden controlar y, también, parcial o totalmente los 
la hora de preverlos. En todo caso, el confuso último inciso del considerando 75 de la Directiva de concesiones ${ }^{62}$, que alude a ciertos supuestos de modificaciones normativas como elementos del riesgo imprevisible, permitiría una conclusión diferente, al menos en determinadas circunstancias. Solución que es trasladable a los supuestos de aplicación de la Directiva sobre contratación pública, ya que no parece admisible introducir por vía interpretativa matizaciones a dos regímenes jurídicos que se han construido de forma refleja.

Por lo demás, la admisibilidad del factum principis puede fundamentarse en el hecho de que el artículo que glosamos no exige que la circunstancia imprevisible sea "externa". Y en la escasa jurisprudencia europea, ya que la STGUE de 31 de enero de 2013, España c. Comisión, T-235/11, considera que el cambio del planeamiento urbanístico no es un hecho imprevisible principalmente porque la Administración estatal, que fue la adjudicadora de la obra, no tomó ninguna iniciativa para tratar de coordinarse con la Administración competente en la aprobación del planeamiento. En otros términos, el hecho de que la "nueva circunstancia" tuviera su origen en una decisión administrativa no la descartaba, por sí misma, como hecho imprevisible.

De imperar una interpretación excesivamente rígida se plantearían supuestos en los que, en caso de no ser posible restablecer el equilibrio económico del contrato, procederá su resolución. Y puede anticiparse que, dado que los elementos obstativos al cumplimiento se sitúan al margen de la esfera de control del contratista, tendrá lugar el consecuente nacimiento del derecho del contratista a percibir una indemnización ${ }^{63}$. En definitiva, como ha señalado Gimeno Feliú (2014, p. 148), deberían concretarse a nivel legal los casos de factum principis, que deben englobar cualquier decisión administrativa (o legislativa) que altere de forma importante el adecuado reparto de riesgos.

riesgos no controlables, pero parece excesivo y desincentivador de las inversiones hacerles asumir los riesgos regulatorios.

62 Literalmente se afirma: "deben ser posibles las modificaciones de la concesión por encima de esos umbrales sin que sea necesario efectuar un nuevo procedimiento de adjudicación en la medida en que esas modificaciones se ajusten a algunos requisitos. Tal sería el caso, por ejemplo, de modificaciones que se hubieran hecho necesarias debido a la necesidad de atender peticiones de los poderes adjudicadores o entidades adjudicadoras en relación con el requisito de seguridad y teniendo presentes las especificidades de las actividades de que se trate, como por ejemplo la explotación de instalaciones turísticas y deportes de montaña, en caso de que la legislación haya evolucionado con el fin de hacer frente a los riesgos correspondientes, en la medida en que esas modificaciones se atengan a los requisitos establecidos en la presente Directiva".

63 Ver conclusiones del Abogado General Albert de 24 de octubre de 2002, en el asunto Succhi di Frutta. Y es que, como se afirma en el apartado 70, con arreglo a las disposiciones de derecho civil, el derecho a una indemnización por daños y perjuicios nace en caso de imposibilidad o incumplimiento de las obligaciones contractuales en el marco de la posterior ejecución del contrato. 


\section{CONSIDERACIONES FINALES}

En el derecho español ius variandi y riesgo imprevisible se han considerado dos figuras técnicamente netamente distintas. Sin embargo, el derecho de la Unión Europea regula ambas bajo un concepto amplio de modificación del contrato. Es preciso destacar que mientras que las posibilidades de ejercitar el ius variandi en el derecho de la Unión son tan limitadas que puede cuestionarse si realmente la modificación del contrato sigue constituyendo una prerrogativa administrativa, la posibilidad de adaptar el contrato a circunstancias imprevisibles está dotada de un margen nada desdeñable de flexibilidad. Dicho en otros términos, las directivas sobre contratación pública pretenden hallar un delicado equilibrio entre las causas y los efectos de los modificados, de forma que la presencia de causas cualificadas permite transformar con más intensidad el contrato inicial, modulando aspectos cuya alteración estaría vedada cuando es una razón "ordinaria" de interés público la que el cambio reclama.

El derecho de la contratación pública de la Unión Europea no protege al contratista, sino a los licitadores. Por ello, las nuevas directivas no reconocen el derecho del adjudicatario a mantener el equilibrio económico del contrato sino que -antes al contrario- se ciñen a fijar los límites que los ordenamientos nacionales deben respetar allí donde reconozcan este derecho. Así, tan conforme es con el derecho de la Unión Europea que determinados Estados reconozcan la doctrina del riesgo imprevisible, sometida a ciertos límites, como que prevean que se cubran ciertos riesgos mediante la imposición al adjudicatario de la obligación de suscribir un contrato de seguros, posibilidad que en algún momento se hizo explícita durante la tramitación de la directiva en estudio. Es igualmente lícito que los derechos nacionales delimiten las circunstancias en las cuales podrá alterarse el contenido del contrato ante un hecho imprevisible. En esta línea, como vimos, el derecho español establece un requisito adicional para la aplicación del riesgo imprevisible, y es que la circunstancia imprevista tenga un impacto relevante y ordinario en la economía del contrato.

En consecuencia, la doctrina de la imprevisión manejada en derecho español no requiere ser sometida a una nueva revisión. Los límites que introducen de manera explícita las nuevas directivas sobre contratación pública no son completamente extraños a la jurisprudencia española, que había realizado un esfuerzo loable para dotar de objetividad al concepto de imprevisibilidad. De este modo, el parámetro para determinar si la circunstancia es o no previsible será atender a si las partes han cumplido los estándares de diligencia que les son exigibles. Se tratará por tanto de un juicio que habrá de realizarse con moderación caso a caso, teniendo en cuenta, sin embargo, que el derecho al reequilibrio en los casos de alteración sobrevenida de las circunstancias no sólo es común a contratos administrativos y concesiones, sino que no es una técnica excepcional en tanto en cuanto hunde sus raíces en el propio principio rebus sic stantibus. 


\section{BIBLIOGRAFÍA}

Albiez Dohrmann, K. J. (2013). Comentario al art. 1593. En BerCovitz Rodríguez CAno (dir.). Comentarios al Código Civil. Valencia: Tirant lo Blanch.

Amenós Álamo, J. y Nieto Moreno, J. E. (2012). La languideciente vida del principio de equilibrio económico del contrato frente a riegos imprevisibles de la contratación pública. REDA, 156, 2012.

ARIÑO, G. (1968). Teoría del equivalente económico de los contratos administrativos, Instituto de Estudios Administrativos.

Arrowsmith, S. (2005). The Law of Public and Utilities Procurement. London: Sweet and Maxwell.

Bernal Blay, M. A. (2011). Reflexiones sobre el régimen de ejecución de los contratos públicos. En Gimeno Feliú. Observatorio de los Contratos Públicos 2010. Civitas.

Castiñeira JÉREZ, (2012). Pacta sunt servanda, imprevisión contractual y alteración sobrevenida de las circunstancias. Revista Aranzadi de Derecho Patrimonial, 29.

Díez SASTRE, S. (2015). El régimen de modificación de los contratos públicos. Los nuevos límites del ius variandi y de la autonomía de la voluntad. AlMEIDA y MARTín (dirs.). El nuevo Derecho de la Contratación Pública. Campus na Nube.

FERnÁndeZ García, J. F. (2014). Equilibrio económico y revisión de precios en los contratos administrativos. REDA, 163.

Gallego CórCOles, I. (2012). La ampliación del plazo concesional como fórmula del restablecimiento económico del contrato. Contratación Administrativa Práctica, 118.

Gallego CórColes, I. (2015). La modificación en la cuarta generación de Directivas sobre contratación pública. Observatorio de los Contratos Públicos. Las nuevas Directivas de Contratación Pública. Aranzadi.

García de EnTERría, E. (1950). Riesgo y ventura y fuerza mayor en el contrato administrativo. Revista de Administración Pública, 2.

García de Enterría, E. y FernándeZ, T. R. (2011). Curso de Derecho Administrativo I. 15. ${ }^{\text {a }}$ ed. Civitas.

Gimeno Feliú, J. M. (2014). El nuevo paquete legislativo comunitario sobre contratación pública. De la burocracia a la estrategia. Thomson Reuters.

Gimeno Feliú, J. M. (2013). La modificación de los contratos: límites y derecho aplicable. La contratación Pública: problemas actuales. CANO CAMPOS y BilBAO AlEXIADES (coords.). Consejo Consultivo de la Comunidad de Madrid. 
Gimeno Feliú, J. M. (2015). La reforma comunitaria en materia de contratos públicos y su incidencia en la legislación española. Una visión desde la perspectiva de la integridad. Observatorio de los Contratos Públicos. Las nuevas Directivas de Contratación Pública. Aranzadi.

Gimeno Feliú, J. M. (2011). El régimen de modificación de los contratos públicos: regulación actual y perspectivas de cambio. REDA, 149.

GonZÁlez-Varas IbÁÑeZ, S. (2003). El contrato administrativo. Civitas.

Harten K., Liljenbol, M. W. (2013). Changes to Existing Contracts Under the EU Public Procurement Rules and the Drafting of Review Clauses to Avoid the Need for a New Tender. PPLR, 22.

Hernández González, F. (2015). La nueva Directiva de concesiones. Un largo viaje con final esperado. Observatorio de los Contratos Públicos. Las nuevas Directivas de Contratación Pública. Aranzadi.

Horgué BAEnA, C. (1997). La modificación del contrato del contrato administrativo de obra. Marcial Pons.

Medina Alcoz, L. (2014). Fundamentos político-constitucionales del Derecho público de los contratos. M. YzQuierdo (dir.). Contratos, t. XIV, Contratos Públicos. Aranzadi.

Mellado Ruiz, L. (2010). El nuevo (y necesario) régimen de modificación de los contratos administrativos en el Proyecto de Ley de Economía Sostenible. Contratación Administrativa Práctica, 99.

Moreno Molina, J.A. (2006). Los principios generales de la contratación de las Administraciones públicas. Bomarzo.

Moreno Molina, J.A. (2013). La cuarta generación de Directivas de la Unión Europea sobre contratos públicos. Gimeno Feliú (dir.). Observatorio de Contratos Públicos 2012. Civitas.

Moreno Molina, J.A. (2015). Análisis comparado de la legislación sobre contratos administrativos de los países de Iberoamérica. Gimeno Feliú (dir.). Observatorio de Contratos Públicos 2014. Civitas.

Ortega Álvarez, L. (2009). El régimen común de equilibrio de económico de concesión de obras públicas predicable de los diferentes supuestos de riesgo y ventura existentes en las diferentes fases de dicha concesión. Puerta SEGuido (dir.). El contrato de concesión de obras públicas en la Ley de Contratos del Sector Público. La Ley.

PoulsEn, S. T. (2012). The possibilities of amending a public contract without a new competitive tendering procedure under EU law. PPLR, 21. 
Puerta Seguido, F. E. (2012). El régimen de la modificación de los contratos del sector público en el Real Decreto legislativo 3/2011, texto refundido de la ley de contratos del sector público. Gimeno Feliú (dir.). Observatorio de Contratos Públicos 2011. Civitas.

Punzón Moraleda, J. y SÁnchez RodríGuez, F. (2012). El equilibrio económico de los contratos públicos. Observatorio de los Contratos Públicos 2011. Civitas.

Racca, G. M. y Cavallo Perin, R. (2013). Material Amendments of Public Contracts during their Terms: From Violations of Competition to Symptoms of Corruption. EPPPL, 4 .

SÁnchez Graells, A. (2012). What Need and Logic for a New Directive on Concessions, Particularly Regarding the Issue of Their Economic Balance? European Public Private Partnerships Law Review.

SANTAMARÍA PASTOR, J. A. (2013). La constante e interminable reforma de la normativa sobre contratación pública. REDA, 159.

VÁZQuez Matilla, F. J. (2015). La modificación de los contratos públicos. Aranzadi. 